\title{
Importance of relative humidity in the oxidative ageing of organic aerosols: case study of the ozonolysis of maleic acid aerosol
}

\author{
P. J. Gallimore ${ }^{1}$, P. Achakulwisut ${ }^{1}$, F. D. Pope ${ }^{1}$, J. F. Davies ${ }^{1, *}$, D. R. Spring ${ }^{1}$, and M. Kalberer ${ }^{1}$ \\ ${ }^{1}$ Department of Chemistry, University of Cambridge, Lensfield Road, Cambridge, CB2 1EW, UK \\ *now at: The School of Chemistry, University of Bristol, Bristol, BS8 1TS, UK
}

Received: 9 August 2011 - Published in Atmos. Chem. Phys. Discuss.: 17 August 2011

Revised: 11 November 2011 - Accepted: 21 November 2011 - Published: 7 December 2011

\begin{abstract}
Many important atmospheric aerosol processes depend on the chemical composition of the aerosol, e.g. water uptake and particle cloud interactions. Atmospheric ageing processes, such as oxidation reactions, significantly and continuously change the chemical composition of aerosol particles throughout their lifetime. These ageing processes are often poorly understood. In this study we utilize an aerosol flow tube set up and an ultra-high resolution mass spectrometer to explore the effect of relative humidity $(\mathrm{RH})$ in the range of $<5-90 \%$ on the ozonolysis of maleic acid aerosol which is employed as model organic aerosol system. Due to the slow reaction kinetics relatively high ozone concentrations of 160-200 ppm were used to achieve an appreciable degree of oxidation of maleic acid. The effect of oxidative ageing on the hygroscopicity of maleic acid particles is also investigated using an electrodynamic balance and thermodynamic modelling. RH has a profound effect on the oxidation of maleic acid particles. Very little oxidation is observed at $\mathrm{RH}<50 \%$ and the only observed reaction products are glyoxylic acid and formic acid. In comparison, when $\mathrm{RH}>50 \%$ there are about 15 oxidation products identified. This increased oxidation was observed even when the particles were exposed to high humidities long after a low RH ozonolysis reaction. This result might have negative implications for the use of water as an extraction solvent for the analysis of oxidized organic aerosols. These humiditydependent differences in the composition of the ozonolyzed aerosol demonstrate that water is both a key reactant in the oxidation scheme and a determinant of particle phase and hence diffusivity. The measured chemical composition of the processed aerosol is used to model the hygroscopic growth,
\end{abstract}

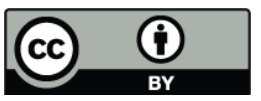

Correspondence to: M. Kalberer (markus.kalberer@atm.ch.cam.ac.uk) which compares favourably with water uptake results from the electrodynamic balance measurements. A reaction mechanism is presented which takes into account the RH dependent observations. This study emphasises the importance of studying the combined effects of several atmospheric parameters such as oxidants and RH to accurately describe the complex oxidation scheme of organic aerosols.

\section{Introduction}

Aerosol particles are an important component of the climate system. They influence the radiative balance of the Earth by light scattering and absorption and through indirect processes such as cloud formation. Most of these aerosol effects are poorly understood, partly due to the large spatial and temporal variability of aerosol particles in the atmosphere but also because of their poorly defined sources and chemical composition, which influence critically all the above processes. Organic compounds are often a dominant fraction of tropospheric aerosol. A significant fraction, up to $10 \%$, of the organic mass is composed of carboxylic acids ( $\mathrm{Li}$ and $\mathrm{Yu}$, 2005; Kawamura et al., 2010), which are emitted directly into the atmosphere but are also formed through oxidation reactions in the atmosphere. In the ambient atmosphere oxalic acid, the smallest dicarboxylic acid, is often the most abundant carboxylic acid with concentrations up to the low $\mu \mathrm{g} \mathrm{m}^{-3}$ range and many other mono- and dicaboxylic acids are present in concentration ranges of $10-100 \mathrm{ng} \mathrm{m}^{-3}$ ( $\mathrm{Li}$ and Yu, 2005; Kawamura et al., 2010). In laboratory experiments it was found that carboxylic acids may account for up to $20-40 \%$ of the total organic mass of photochemically generated secondary organic aerosols (Fisseha et al., 2004). Carboxylic acids are among the most water-soluble organic

Published by Copernicus Publications on behalf of the European Geosciences Union. 
aerosol components and therefore are important when considering hygroscopic particle properties and aerosol cloud interactions. The atmospheric fate of carboxylic acids, e.g. their further oxidation in atmospheric aerosols, and the effect of such oxidation reactions on water uptake, are not well understood.

Oleic acid, a long-chain fatty acid, has been used frequently as a model aerosol system to investigate the oxidation of unsaturated carboxylic acids and has recently been reviewed by Zahardis and Petrucci (2007). The mechanism for the generation of stable first-generation oxidation products including aldehydes and carboxylic acids are well understood (Ziemann, 2005; Vesna et al., 2009; Last et al., 2009). Aldehydes may be of sufficient volatility to partition from the particle into the gas phase (Vesna et al., 2009) whereas the carboxylic acid oxidation products remain in the particle phase due to their low vapour pressure. A very slight increase in hygroscopicity is observed after oxidative processing of the oleic acid particles due to the carboxylic acid oxidation products (Vesna et al., 2008) and differences in the distribution of oxidation products were observed at different RH. Besides the simple break down products of oleic acid, a large number of higher molecular weight reaction products have been observed and structures have been postulated (Ziemann, 2005; Reynolds et al., 2006; Last et al., 2009). Ozonolysis reactions of other unsaturated carboxylic acids such as arachidonic acid, linoleic acid and linolenic acid have been investigated as model systems for organic aerosols, and changes in particle mass, hygroscopicity, and morphology were observed (Lee and Chan, 2007; Vesna et al., 2008).

Very recently Nguyen et al. (2011) observed significant differences in the composition of secondary organic aerosol formed during isoprene oxidation under dry and wet conditions and Kamens et al. (2011) also observed differences for wet and dry secondary organic aerosol formation from toluene.

Maleic acid, a small, unsaturated di-carboxylic acid, is another model compound which has been used in laboratory experiments with the aim to identify oxidation reaction schemes typical for organic aerosols. Maleic acid is also found in ambient particles in the low $\mathrm{ng} \mathrm{m}^{-3}$ concentration range (e.g. Kundu et al., 2010). In laboratory ozonolysis experiments of maleic acid a range of small oxidation products such as formic acid, glyoxylic acid, glyoxal, oxalic acid and $\mathrm{CO}_{2}$ have been observed (Najera et al., 2009; Last et al., 2009; Leitzke and von Sonntag, 2009). The rate of formic acid formation was observed to be higher for aqueous particles compared to dry particles but no changes of reaction products were identified (Najera et al., 2010).

In an earlier paper we investigated the effect of the ozonolysis of maleic acid particles upon the particle hygroscopicity using a single particle electrodynamic balance (Pope et al., 2010a). Besides an expected increase in hygroscopicity after exposure to ozone, the particle phase (i.e. aqueous versus solid) had a significant effect on the particle oxidation: particles exposed to ozone under dry conditions appear to undergo additional chemical processing upon deliquescence after ozone exposure. Volatilisation and particle mass loss is observed only after a full deliquescence event, even if the exposure of the particle to ozone stopped hours before the humidity was changed. After multiple relative humidity (RH) cycles the hygroscopicity closely resembles particles obtained from ozonolysis under high-humidity conditions. Ozonolysis of maleic acid particles under dry conditions did not result in a measurable loss of volatile compounds. The general shape of the humidograms and the deliquescence point agreed well with thermodynamic predictions using the Extended Aerosol Inorganics Model (E-AIM, http: //www.aim.env.uea.ac.uk/aim/aim.php) (Wexler and Clegg, 2002).

The study presented here investigates the RH dependent ozonolysis of maleic acid aerosols using an aerosol flow tube reactor. An ultra-high resolution mass spectrometer is used to characterize the reaction products. A reaction mechanism is presented, which accounts for the observed differences in reactivity in the absence and presence of water in the particle. We rationalize the EDB hygroscopic growth data presented in Pope et al. (2010a) using the chemical analyses and the mechanism developed in the current study.

\section{Experimental}

\subsection{Aerosol generation and processing}

A schematic of the experimental set-up is shown in Fig. 1. The aerosol particles were prepared from an aqueous solution of maleic acid in deionised water $\left(0.1 \mathrm{moll}^{-1}\right.$, purity: $99 \%$, Fluka, Buchs, Switzerland) using a custom-built nebuliser (Fig. 1a). Dry nitrogen (BOC Gases, Guildford, UK) at 3 bar pressure was used to generate the aerosol flow. The output flow rate at atmospheric pressure was $1.41 \mathrm{~min}^{-1}$. The aerosol was passed through a pair of silica bead diffusion driers in series to produce an aerosol with an $\mathrm{RH}<5 \%$.

Ozone was generated by flowing synthetic air (Zero grade, BOC) through a pair of photolysis tubes connected in parallel, each containing a $185 \mathrm{~nm}$ UV light source (Appleton Woods, Birmingham, UK). The combined $2.01 \mathrm{~min}^{-1}$ airflow contained ozone at a concentration of 160-200 ppm. The ozone concentration was determined using a UV photometric ozone analyser (Thermo Scientific model 49i; Waltham, USA) with detection range $1 \mathrm{ppb}-200 \mathrm{ppm}$. Air samples were pre-diluted with additional zero air prior to ozone analysis to avoid taking measurements close to the upper detection limit of the ozone analyzer. Ozone concentrations were measured before and after each ozonolysis experiment to check the temporal stability of the ozone concentration.

Initial experiments at low ozone concentrations and short reaction times $(20 \mathrm{~min})$ did not result in significant 
(a) Aerosol and ozone generation:

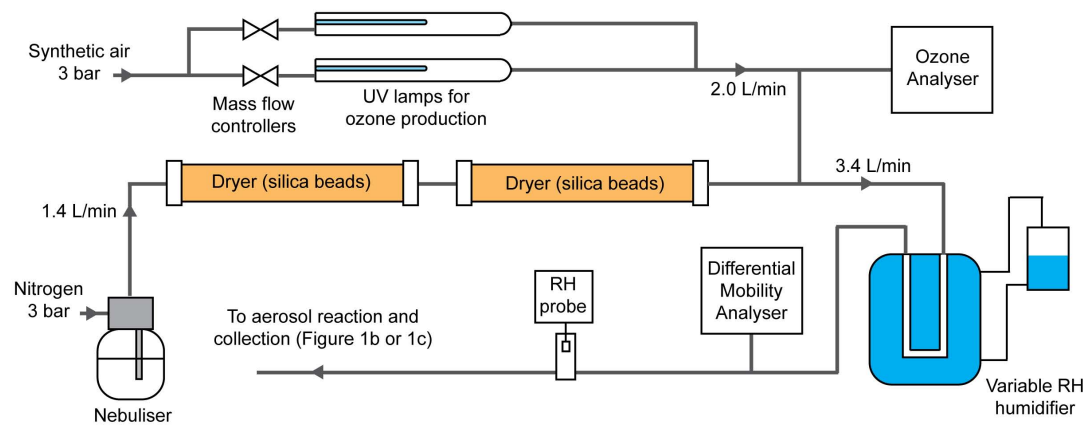

(b) Reactions in the aerosol phase:

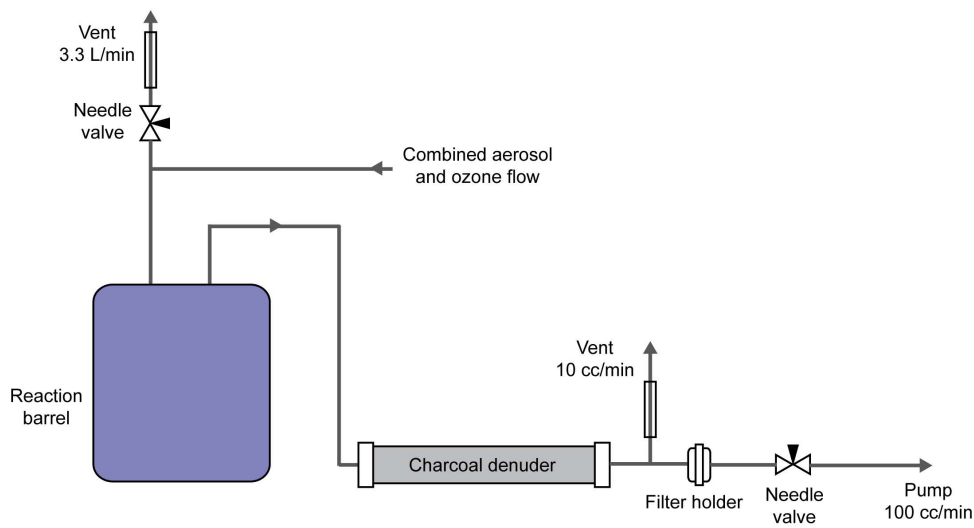

(c) Reactions on the filter:

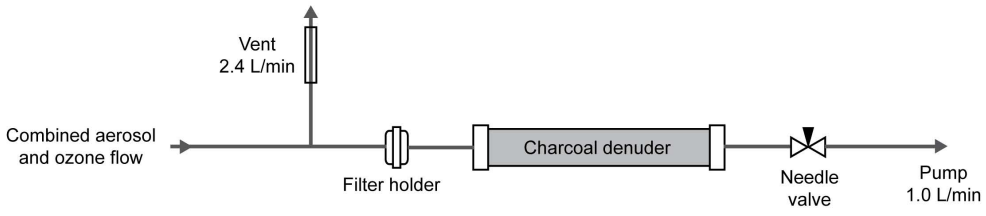

Fig. 1. Schematic diagram of the aerosol flow tube apparatus. Aerosol and ozone flows were generated, humidified (a) and reacted in a 501 barrel (b) or were reacted on a filter (c).

processing of maleic acid. The conjugated structure of maleic acid is proposed to stabilize the $\mathrm{C}-\mathrm{C}$ double bond and slows down the reaction kinetics considerably compared to other aerosol model systems with unsaturated organic compounds, e.g. oleic acid. Therefore for all experiments discussed here a long reaction time $(3-7.5 \mathrm{~h})$ and relatively high ozone concentrations (160-200 ppm) were used to achieve an appreciable degree of oxidation of maleic acid. The observed oxidation products (see Table 1 and related discussion below) do not involve multiple oxidation steps with ozone and thus it is assumed that the mechanistic results presented here are also valid for lower atmospheric ozone concentrations.

The RH of the mixed ozone and aerosol flows was controlled using a custom-built humidifier consisting of a GoreTex membrane tube housed in a container; the water level in the container was varied to change the proportion of tube immersed. The RH could be varied between $<5 \%$ and $95 \%$. The RH of the combined flow was measured with a humidity and temperature probe (Vaisala model HMP143A; Helsinki, Finland).

The aerosol was characterised using a differential mobility analyser (DMA) (Hauke model VIE-08; Gmunden, Austria) coupled to a Faraday cup electrometer (Hauke FCE-08A). The size distribution was measured before and after each ozonolysis experiment. Stable unimodal particle size distributions with a mode at $75 \mathrm{~nm}$ (FWHM: $130 \mathrm{~nm}$ ) and particle concentration of $2 \times 10^{6}$ particles $\mathrm{cm}^{-3}$ were typically measured.

During ozonolysis experiments, a small vent flow to the fume hood was maintained prior to the particle filter by setting the pump flow rate slightly below the combined input flow rates. The vent flow rate was monitored using a flow meter (GPE, Leighton Buzzard, UK). The flow meter creates only a very minor pressure drop, which ensures that the entire flow apparatus operates essentially at ambient pressure. The temperature of the aerosol flow tube was not regulated 
and was determined by the room temperature. The lab is air conditioned and the temperature was approximately $20^{\circ} \mathrm{C}$.

Two types of experiments were performed. In one set of experiments the maleic acid particles were oxidized in the aerosol phase only and in another set of experiments particles were reacted with ozone on a Teflon filter, which allowed the collection of more particles for the mass spectrometry analysis (see Fig. 1b and c). For the particles oxidized in the aerosol phase only (Fig. 1b), a large reaction barrel (501) with a mixing fan was used as a reaction volume. An additional vent was introduced before the barrel to divert the majority of the flow $\left(3.31 \mathrm{~min}^{-1}\right)$ to exhaust and to reduce the flow rate through the barrel to $110 \mathrm{~cm}^{3} \mathrm{~min}^{-1}$. The resulting reaction time between aerosol and ozone in the flow apparatus was approximately $7.5 \mathrm{~h}$, which was estimated by the volume of the barrel and the flow rate assuming a wellmixed reaction volume. Aerosol particles were collected on a Teflon filter placed behind the barrel for approximately 11 h. A charcoal denuder was placed before the filter holder to remove ozone and volatile organic oxidation products and to stop further oxidation of the particles with ozone on the filter. The use of denuders can potentially shift the equilibrium of compounds which are simultaneously present in the particle and gas phase towards the gas phase. This aspect was not further investigated and could potentially lead to underestimation of particle phase reaction routes. Particle concentrations decreased in the barrel significantly due to coagulation and wall losses. Typical particle concentrations after the reaction time in the barrel were about $10^{4}-10^{5}$ particles $\mathrm{cm}^{-3}$. Experiments were performed at relative humidities of $<5 \%$ and $>90 \%$.

For the experiments where the particles were oxidized mostly on the Teflon filter (Durapore membrane filters, hydrophilic, $0.1 \mu \mathrm{m}$ pore size, Millipore, Watford, UK) the combined aerosol and ozone mixture $\left(1.01 \mathrm{~min}^{-1}\right)$ was pumped over the filter for $30 \mathrm{~min}$, after which time the nebuliser was switched off (Fig. 1c). Ozone was then flowed through the apparatus and over the captured particles on the filter for an additional $150 \mathrm{~min}$ resulting in a total average reaction time of about $3 \mathrm{~h}$. A denuder (activated charcoal) was used to adsorb ozone and gas-phase organic species after the filter to protect the pump, and the resulting airflow was pumped to exhaust. Experiments were performed at relative humidities of $<10,40,60,80 \%$, respectively.

The amount of sample available for analysis in the filterbased experiments was about 2 orders of magnitudes larger compared to the barrel experiments due to wall losses of particles in the barrel. Thus for detailed product identification studies the filter-based samples were mostly used and samples obtained from the barrel experiments were mainly used to confirm that no filter artefacts occurred.

The oxidized maleic acid particles on the filter were extracted by sonication for $30 \mathrm{~min}$ in $2 \mathrm{ml}$ acetonitrile. HPLC-grade acetonitrile was obtained from Fisher Scientific (Loughborough, UK). The $2 \mathrm{ml}$ extracts were stored at $-20^{\circ} \mathrm{C}$ in $7 \mathrm{ml}$ darkened glass vials until analysis by mass spectrometry.

\subsection{Mass spectrometry}

Mass spectra of the filter extracts were obtained in negative ionization mode using an ultra-high resolution mass spectrometer (Orbitrap Velos, Thermo Scientific, Bremen, Germany) with direct infusion and a standard Heated Electrospray Ionisation (HESI) source. The HESI ionisation conditions were set as follows: infusion flow rate $10 \mu \mathrm{min}^{-1}$, Vapouriser temperature $60^{\circ} \mathrm{C}$, Ion transfer tube temperature $275^{\circ} \mathrm{C}$, Spray voltage $-3 \mathrm{kV}$, Sheath gas flow rate 10 arbitrary units, Auxiliary gas flow off. The API stack, Ion optics and Orbitrap mass analyser settings were set according to the manufacturers' defaults.

Mass spectra were acquired with a resolution of 100000 at $m / z 400$ and a accuracy of $<1 \mathrm{ppm}$. This accurate mass determination allows unambiguous determination of the elemental composition of most oxidation products detected, an important step towards product identification.

\section{Results and discussion}

\subsection{Dry and humid ozonolysis}

Figure 2 shows example mass spectra of maleic acid aerosol particles after reaction with ozone, in the 501 barrel reactor under dry $(\mathrm{RH}<5 \%)$ and high $\mathrm{RH}(>90 \%)$ conditions. It is evident that the ozonolysis at high $\mathrm{RH}$ results in a greater number of reaction products. The results of the 501 barrel reactor are largely comparable with the ozonolysis of the maleic acid aerosol deposited on a Teflon filter. Figure 3 shows example mass spectra of maleic acid particles, which are deposited on a Teflon filter and exposed to ozone under dry (10\% RH) and high RH $(80 \%)$ conditions. Under dry conditions identical mass spectra were obtained for the aerosol and for the filter experiment and besides maleic acid $(\mathrm{m} / \mathrm{z}, 115.004)$ only one oxidation product, glyoxylic acid $(\mathrm{m} / \mathrm{z}$ 72.993), was detected (Figs. 2a, 3a). The peak at $\mathrm{m} / \mathrm{z}$ 71.014 is a fragment of maleic acid $\left(\mathrm{M}-\mathrm{CO}_{2}\right.$, typical for carboxylic acids), which is also present if pure maleic acid standard solutions are analysed. C-13 peaks of maleic acid and its fragment (at $m / z 116$ and 72, respectively) are also measured. No peaks at $>m / z 200$ were measured.

In contrast $14-18$ peaks with intensities $>1 \%$ relative to the most intensive peak were found when maleic acid particles were oxidised under an elevated relative humidity above about $50 \%$ (see Figs. 2b, 3b, Table 1 and detailed discussion of the reaction mechanisms below). The high mass resolution of the mass spectrometer used here allows for an assignment of a chemically meaningful elemental composition for most of the peaks listed in Table 1 . For the wet oxidation most peaks with relative intensities $>5 \%$ are detected in both types of samples. Only $m / z$ 100.988, dominantly found 

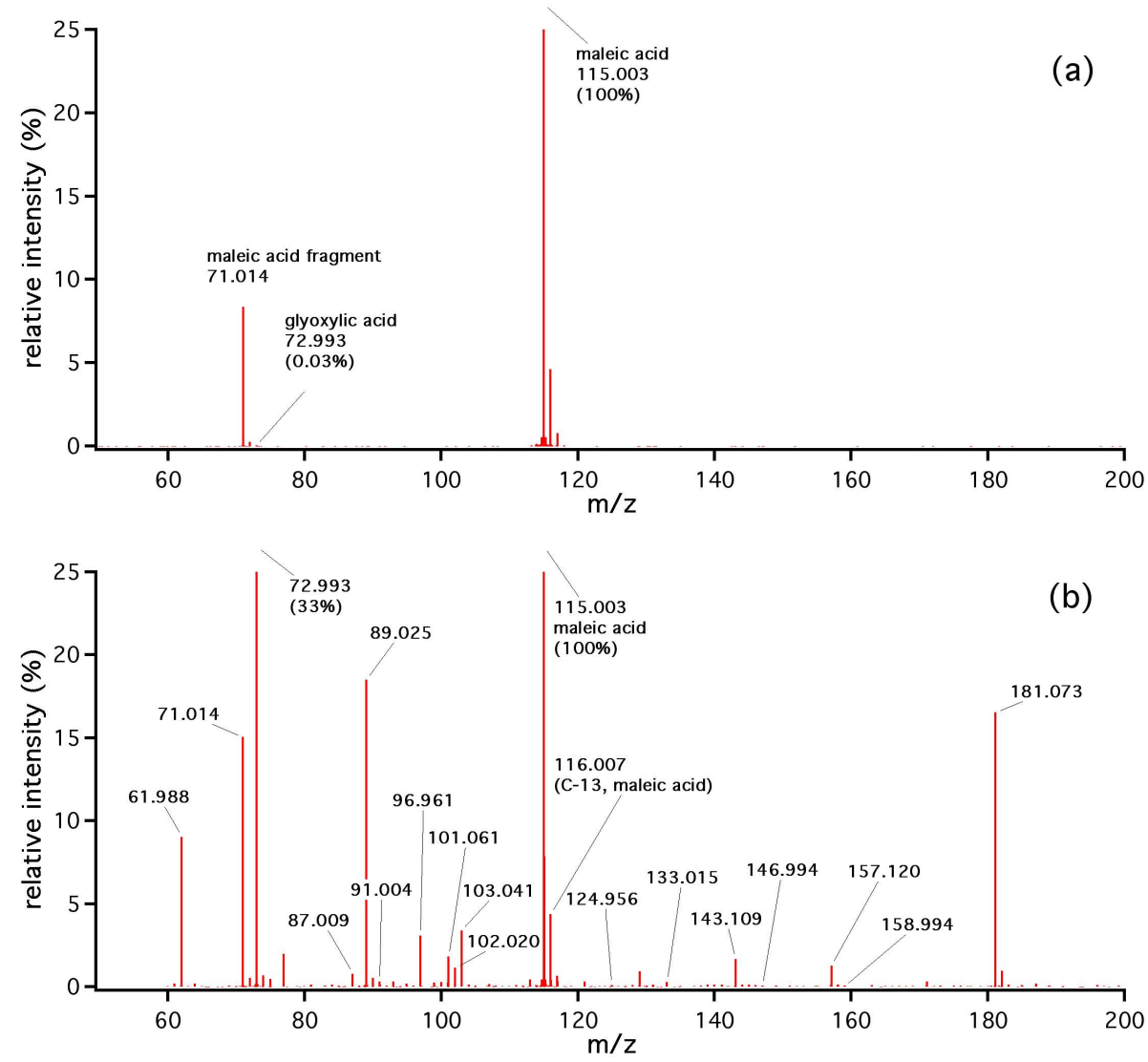

Fig. 2. Mass spectra of the reaction products of the aerosol phase reaction of ozone with maleic acid aerosol in a 501 reaction barrel. Reaction time between ozone and aerosol was approximately $7.5 \mathrm{~h}$. The dry reaction was conducted at $<5 \% \mathrm{RH}$ (a). The wet reaction was conducted at $90 \% \mathrm{RH}$ (b). Post reaction the processed aerosol was collected on a Teflon filter and extracted from the filter in pure acetonitrile.

in the filter experiments is not detected in the aerosol experiment and $\mathrm{m} / \mathrm{z} 89.025$ and 181.073 are measured in high intensities in the aerosol but not in the filter experiment. All other peaks, which are not identical between the two reaction conditions, have relative intensities $<5 \%$.

The overall similarity between the experiments carried out in the 501 barrel reactor and the particles oxidized on the Teflon filter, gives confidence in the ability of the filter experiments to replicate the reactivity of maleic acid aerosol to ozone (see Table 1, last column). Thus, all data discussed below were obtained by the filter method.

Previous studies identified formic acid, glyoxal, glyoxylic acid and oxalic acid as organic oxidation products of maleic acid (Najera et al., 2009, 2010; Last et al., 2009; Leitzke and von Sonntag, 2009). Of these oxidation products we could identify glyoxylic acid (the most intense oxidation product, Figs. 2, 3) and oxalic acid with electrospay ionisation. The mass of formic acid is below the detectable $\mathrm{m} / \mathrm{z}$ range of the Orbitrap Velos mass spectrometer used here $(\mathrm{m} / \mathrm{z}, 50-2000)$ and glyoxal does not ionize efficiently with electrospray and thus both compounds could not be detected with the highresolution mass spectrometer.
The production of formic acid at $50 \%$ RH was confirmed using an electron impact ionisation quadrupole mass spectrometer (EI-MS). Briefly, maleic acid solution was nebulized, mixed with $50 \mathrm{ppm}$ ozone and introduced into a reaction flow tube (volume $=21$ ) allowing for a reaction time of about $50 \mathrm{~s}$. The particle concentration and diameter were similar as stated above. The detection of formic acid with the EI-MS required the pre-concentration of the gas by flowing the gas through a cold trap $\left(-78^{\circ} \mathrm{C}\right.$, dry ice and acetone) for one hour. Once the product gases had been pre-concentrated the trap was warmed and the gases entered the EI-MS.

Last et al. (2009) report about 20 peaks detected in oxidized maleic acid under dry conditions in ethyl acetate solution in a mass range of $m / z, 129-413$ but no further discussion is given. None of these peaks could be confirmed here. This difference could be partly due to the very different reaction conditions: Last et al. investigated dilute maleic acid solutions in an organic solvent, whereas in our study maleic acid particles were oxidized. Najera et al. (2010) did only observe minor differences in composition when maleic acid particles were oxidized under high RH conditions compared to dry oxidation, which is in contrast to the observations here. 

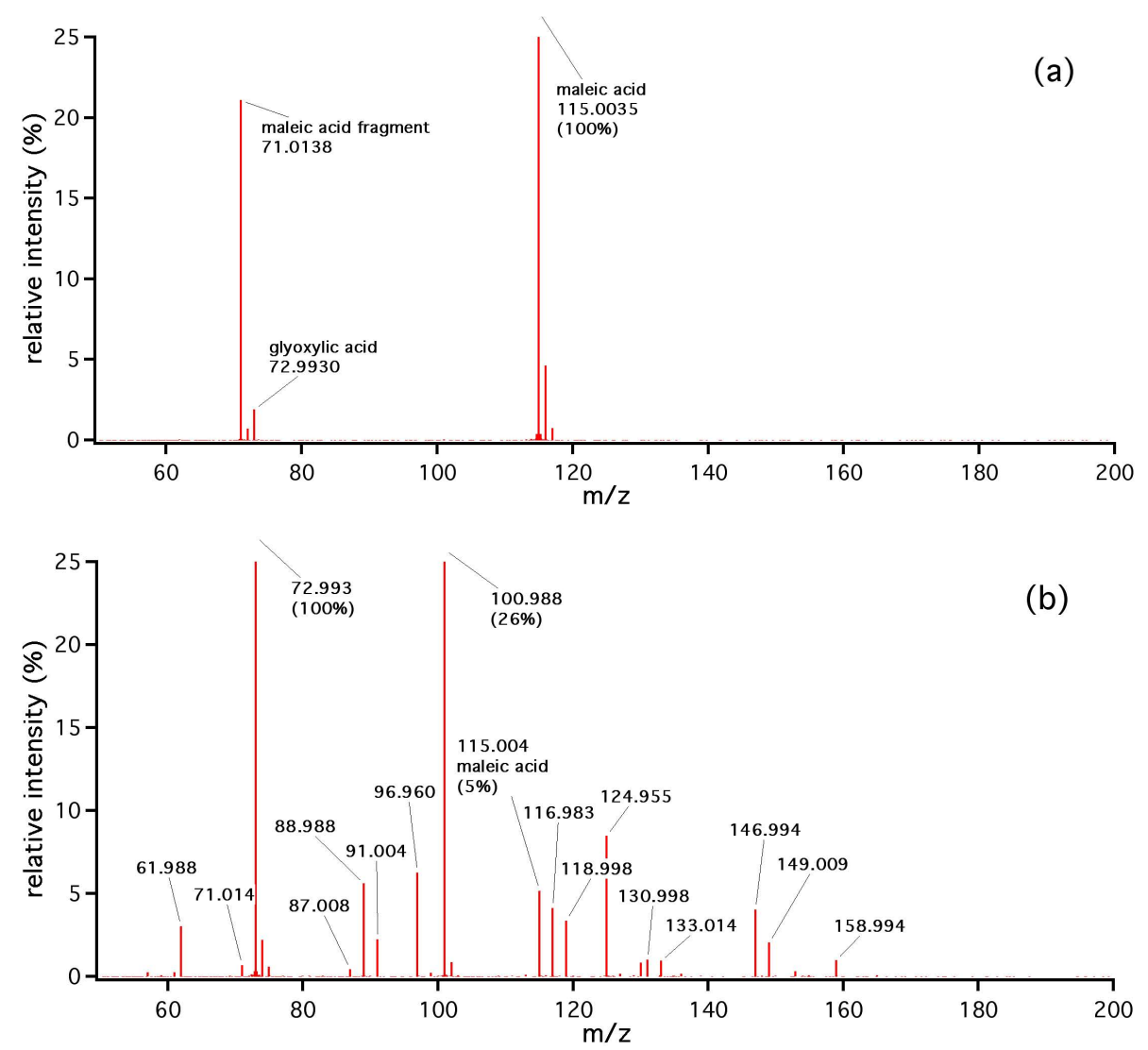

Fig. 3. Mass spectra of the reaction products of ozone and maleic acid particles reacted on a Teflon filter for $3 \mathrm{~h}$. The dry reaction was conducted at $10 \% \mathrm{RH}$ (a). The wet reaction was conducted at $80 \% \mathrm{RH}(\mathbf{b})$. Post reaction the processed particles were extracted with pure acetonitrile. Results of particles oxidized on the filter (Fig. 3) are comparable to results of the real aerosol experiments shown in Fig. 2.

Figure 4a shows the peak intensities of maleic acid $(\mathrm{m} / \mathrm{z}$ 115.0), glyoxylic ( $\mathrm{m} / \mathrm{z}$ 72.9), 2,3-dioxopropanoic (one possible structure for $m / z$ 87.0) and oxalic acid $(\mathrm{m} / \mathrm{z}$ 88.9) relative to the sum of the intensities of all peaks in the mass spectra, which are listed in Table 1 as a function of relative humidity together with the hygroscopic growth curve of pure maleic acid derived from experiments in a single-particle electrodynamic balance (EDB). For clarity only three oxidation products are shown in Fig. 4a but all oxidation products listed in Table 1 show similar trends with increasing RH. Single particles containing a net charge were levitated in the EDB within a synthetic air environment at $295 \mathrm{~K}$. The EDB design follows the double ring electrode architecture of Davis et al. (1989), and a detailed description of the instrument has been given elsewhere (Pope et al., 2010b). The changing mass of the particle, e.g. due to water uptake or loss, can be followed by observing the electric force required to balance the weight of the particle. The figure parameterises the aerosol hygroscopicity as the mass growth factor $\left(\mathrm{m} / \mathrm{m}_{0}\right)$, which is the mass of the particle at a set RH $(m)$ relative to the dry mass of the particle $\left(m_{0}\right) . m / m_{0}$ at $10 \% \mathrm{RH}$ was set to one. No change in water uptake (hygroscopicity) is observed below about $50 \% \mathrm{RH}$ and only a very limited oxidation is observed, i.e. the oxidation products are measured with negligible intensities. At $>50 \% \mathrm{RH}$ a gradual increase in oxidation products is observed consistent with the hygroscopic growth curve. Very little water uptake is observed at RH below the deliquescence point of maleic acid, which occurs at about $85 \% \mathrm{RH}$. This indicates that water is an important reactant involved in the oxidation of maleic acid rather than only serving as a solvent to dissolve the solid maleic acid particle at the deliquescence point; see discussion below.

As discussed in the introduction the hygroscopicity of maleic acid is reasonably well known through laboratory EDB studies (Choi and Chan, 2002; Pope et al., 2010a). The results of the thermodynamic modelling and experimental results of the hygroscopicity of maleic acid under different relative humidities are shown in Fig. 4b. The thermodynamic calculations were performed with the Extended Aerosol Inorganics Model (E-AIM, http://www.aim.env.uea.ac.uk/aim/ aim.php, Clegg et al., 2001). Within E-AIM, the UNIFAC model was used to predict the activity coefficients of the aerosol components and the water activity within the particle as a whole. The UNIFAC model determines the activity 
Table 1. List of peaks observed in the mass spectra from the ozonolysis of maleic acid aerosol under high $\mathrm{RH}$ conditions $(\mathrm{RH}>50 \%)$ with relative peak intensities $>1 \%$.

\begin{tabular}{|c|c|c|c|c|}
\hline $\begin{array}{l}m / z \\
\text { (deprotonated) }\end{array}$ & $\begin{array}{l}\text { Elemental } \\
\text { composition } \\
\text { (neutral) }\end{array}$ & $\begin{array}{ll}\text { Proposed } & \text { structure } \\
\text { and name } & \end{array}$ & $\begin{array}{l}\text { Reaction steps as } \\
\text { shown in Fig. } 6 .\end{array}$ & $\begin{array}{l}\text { Observed in the barrel } \\
\begin{array}{ll}\text { (B) or filter } & \text { (F) } \\
\text { experiments }\end{array}\end{array}$ \\
\hline 61.988 & $*$ & -- & -- & $\mathrm{B}, \mathrm{F}$ \\
\hline 72.993 & $\mathrm{C}_{2} \mathrm{H}_{2} \mathrm{O}_{3}$ & lic acid & $\mathrm{A}$ & $\mathrm{B}, \mathrm{F}$ \\
\hline 87.008 & $\mathrm{C}_{3} \mathrm{H}_{4} \mathrm{O}_{3}$ & 3-oxopropanoic acid & $\begin{array}{l}\text { D } \\
\text { D }\end{array}$ & $\mathrm{B}, \mathrm{F}$ \\
\hline 88.988 & $\mathrm{C}_{2} \mathrm{H}_{2} \mathrm{O}_{4}$ & oxalic acid & Fig. 7 & $\mathrm{~F}$ \\
\hline 89.025 & $\mathrm{C}_{3} \mathrm{H}_{6} \mathrm{O}_{3}$ & -- & -- & B \\
\hline 91.004 & $\mathrm{C}_{2} \mathrm{H}_{4} \mathrm{O}_{4}$ & $\begin{array}{l}\text { glyoxylic acid } \\
\text { hydrate }\end{array}$ & Fig. 7 & $\mathrm{~B}, \mathrm{~F}$ \\
\hline 96.960 & $*$ & -- & -- & $\mathrm{B}, \mathrm{F}$ \\
\hline 100.988 & $\mathrm{C}_{3} \mathrm{H}_{2} \mathrm{O}_{4}$ & $\begin{array}{l}\text { 2,3-dioxopropanoic } \\
\text { acid }\end{array}$ & B & $F$ \\
\hline 101.062 & $*$ & -- & -- & $\mathrm{B}$ \\
\hline 102.020 & $*$ & -- & -- & $\mathrm{B}$ \\
\hline 103.041 & $\mathrm{C}_{4} \mathrm{H}_{8} \mathrm{O}_{3}$ & -- & -- & B \\
\hline 115.004 & $\mathrm{C}_{4} \mathrm{H}_{4} \mathrm{O}_{4}$ & & $\mathrm{~A}$ & $\mathrm{~B}, \mathrm{~F}$ \\
\hline 116.983 & $\mathrm{C}_{3} \mathrm{H}_{2} \mathrm{O}_{5}$ & 2-oxomalonic acid & B & $\mathrm{F}$ \\
\hline 118.998 & $\mathrm{C}_{3} \mathrm{H}_{4} \mathrm{O}_{5}$ & or of & \begin{tabular}{|l} 
C \\
B \\
Fig. 7
\end{tabular} & $\mathrm{~F}$ \\
\hline
\end{tabular}


Table 1. Continued.

\begin{tabular}{|c|c|c|c|c|}
\hline $\begin{array}{l}m / z \\
\text { (deprotonated) }\end{array}$ & $\begin{array}{l}\text { Elemental } \\
\text { composition } \\
\text { (neutral) }\end{array}$ & $\begin{array}{ll}\text { Proposed } & \text { structure } \\
\text { and name } & \end{array}$ & $\begin{array}{l}\text { Reaction steps as } \\
\text { shown in Fig. } 6 .\end{array}$ & $\begin{array}{l}\text { Observed in the barrel } \\
\begin{array}{l}\text { (B) or filter } \quad(F) \\
\text { experiments }\end{array}\end{array}$ \\
\hline 124.955 & * & -- & -- & $\mathrm{B}, \mathrm{F}$ \\
\hline 130.998 & $\mathrm{C}_{4} \mathrm{H}_{4} \mathrm{O}_{5}$ & 2-oxosuccinic acid & $\begin{array}{l}\text { D } \\
\text { D } \\
\text { Fig. } 7\end{array}$ & F \\
\hline 133.014 & $\mathrm{C}_{4} \mathrm{H}_{6} \mathrm{O}_{5}$ & & $\mathrm{D}$ & $F$ \\
\hline 143.109 & $* *$ & & & B \\
\hline 146.994 & $\mathrm{C}_{4} \mathrm{H}_{4} \mathrm{O}_{6}$ & & $\begin{array}{l}\text { Fig. } 7 \\
\text { Fig. } 7\end{array}$ & $\mathrm{~B}, \mathrm{~F}$ \\
\hline 149.009 & $\mathrm{C}_{4} \mathrm{H}_{6} \mathrm{O}_{6}$ & $\mathrm{OI}$ & Fig. 7 & $\mathrm{~F}$ \\
\hline 157.120 & $* *$ & -- & -- & B \\
\hline 158.994 & $\mathrm{C}_{5} \mathrm{H}_{4} \mathrm{O}_{6}$ & -- & -- & $\mathrm{B}, \mathrm{F}$ \\
\hline 165.004 & $\mathrm{C}_{4} \mathrm{H}_{6} \mathrm{O}_{7}$ & $\begin{array}{l}{ }^{2} \\
\text { or }\end{array}$ & $\begin{array}{l}\text { Fig. } 7 \\
\text { Fig. } 7 \\
\text { Fig. } 8\end{array}$ & F \\
\hline 181.073 & $*$ & 01 & -- & B \\
\hline 183.01 & $\mathrm{C}_{4} \mathrm{H}_{8} \mathrm{O}_{8}$ & & Fig. 8 & $\mathrm{~F}$ \\
\hline
\end{tabular}

* No likely chemically elemental composition could be determined within the instrument mass accuracy and when considering only $\mathrm{C}, \mathrm{H}$ and $\mathrm{O}$.

** Peaks present in solvent. 
coefficients of the mixture components by the interactions of the structural groups within each component (Wittig et al., 2003). The modified UNIFAC parameter values of Peng et al. (2001) were used, and justification of the Peng values is given elsewhere (Pope et al., 2010b, c). The measured humidograms were reported in our previous paper (Pope et al., 2010a). We did not attempt to account for the difference in temperature between the measured $\left(22^{\circ} \mathrm{C}\right)$ and modelled system $\left(25^{\circ} \mathrm{C}\right)$.

The modelled hygroscopicity of pure maleic acid gives a sharp deliquescence point at $88 \% \mathrm{RH}$, whereas the laboratory measured deliquescence occurs gradually between 83 $88 \%$ RH (Fig. 4b). The small mass increase below $80 \%$ RH as shown in Fig. 4a is hardly visible here due to the different scale of the $y$-axis. Upon exposure to ozone $(<1.6 \mathrm{ppm})$ the measured deliquescence point of maleic acid aerosol is lowered, with significant water uptake occurring already at $\sim 65 \%$ RH (Fig. 4b), which indicates the formation of compounds with a lower deliquescence point than maleic acid.

The relative intensities of maleic acid, glyoxylic acid and 2,3-dioxopropanoic acid within the mass spectra at 10, 40, 60 and $80 \%$ RH (Fig. 4a) were used to model the water uptake of the processed aerosol, assuming equal ionization efficiencies of the compounds, i.e. assuming that the relative intensities of the mass spectral peaks are proportional to the mole fractions of the compounds in the aerosol particles. It was found that the water uptake of the processed aerosol could be represented using these three components (maleic acid, glyoxylic acid and 2,3-dioxopropanoic acid), which accounted for $100,99.8,94.6$, and $85.1 \%$ of the total ion current in the mass spectra when the aerosol processing was conducted at $10,40,60$ and $80 \% \mathrm{RH}$, respectively. The liquid phase water activities of the glyoxylic acid and 2,3-dioxopropanoic acid were estimated using UNIFAC with the modified parameter values of Peng et al. (2001).

Only minor differences are observed in the composition between pure maleic acid and that of aerosol particles ozonolysed at $40 \% \mathrm{RH}$ and below, which is reproduced in the modelled hygroscopicity. When ozonolysis was performed at $60 \% \mathrm{RH}$ and above the significant changes in the aerosol composition are reflected by significant changes in the predicted and measured aerosol hygroscopicity. The differences in the measured and modelled hygroscopic growth between $50 \%$ and $70 \% \mathrm{RH}$ for a particle exposed to ozone might be due to limitations of the model (e.g. the assumption of equal ionization probabilities to estimate the particle composition) or due to kinetically hindered water uptake into a possibly highly viscous aqueous layer at the surface of the particle at these intermediate humidities, which would result in a low bias of the experimental result. The influence of particle diffusivity on the reactivity of particles was recently demonstrated in a modelling study by Pfrang et al. (2011) and Shiraiwa et al. (2011).

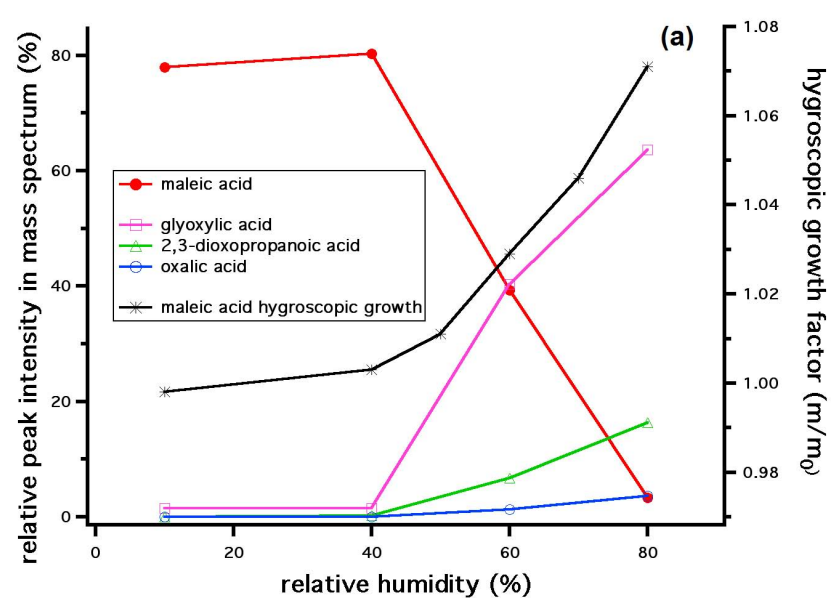

(b)

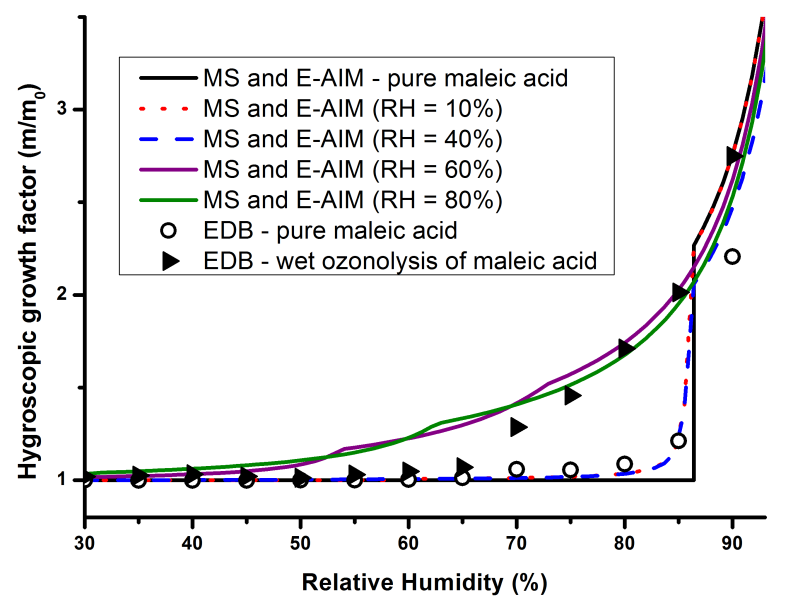

Fig. 4. (a) Relative peak intensities of maleic acid and three oxidation products are shown as a function of relative humidity (left $y$-axis) as well as the hygroscopic growth factor of pure maleic acid as a function of humidity (right y-axis). Below $50 \% \mathrm{RH}$ negligible hygroscopic growth occurs and the yield of oxidation products is very low. Above $50 \% \mathrm{RH}$ water associated with the aerosol leads to an increased yield of oxidation products demonstrating the close link of hygroscopicity and chemical composition. (b) Measured and modelled mass growth humidograms for pure maleic acid aerosol and of maleic acid under wet ozonolysis conditions. The predicted growth curves use the mass spectrometry data to estimate aerosol composition and hence hygroscopicity. All data is for the deliquescence growth mode. Black line - predicted growth curve for pure maleic acid. Red dotted line - predicted growth curve for maleic acid aerosol ozonolysed at $10 \% \mathrm{RH}$. Blue dashed line - predicted growth curve for maleic acid ozonolysed at $40 \% \mathrm{RH}$. Purple line - predicted growth curve for maleic acid ozonolysed at $60 \% \mathrm{RH}$. Green line - predicted growth curve for maleic acid ozonolysed at $80 \%$ RH. Open circles - measured growth curve for pure maleic acid. Closed triangles - measured growth curve for maleic acid aerosol which had been ozonolysed in its deliquesced phase. 

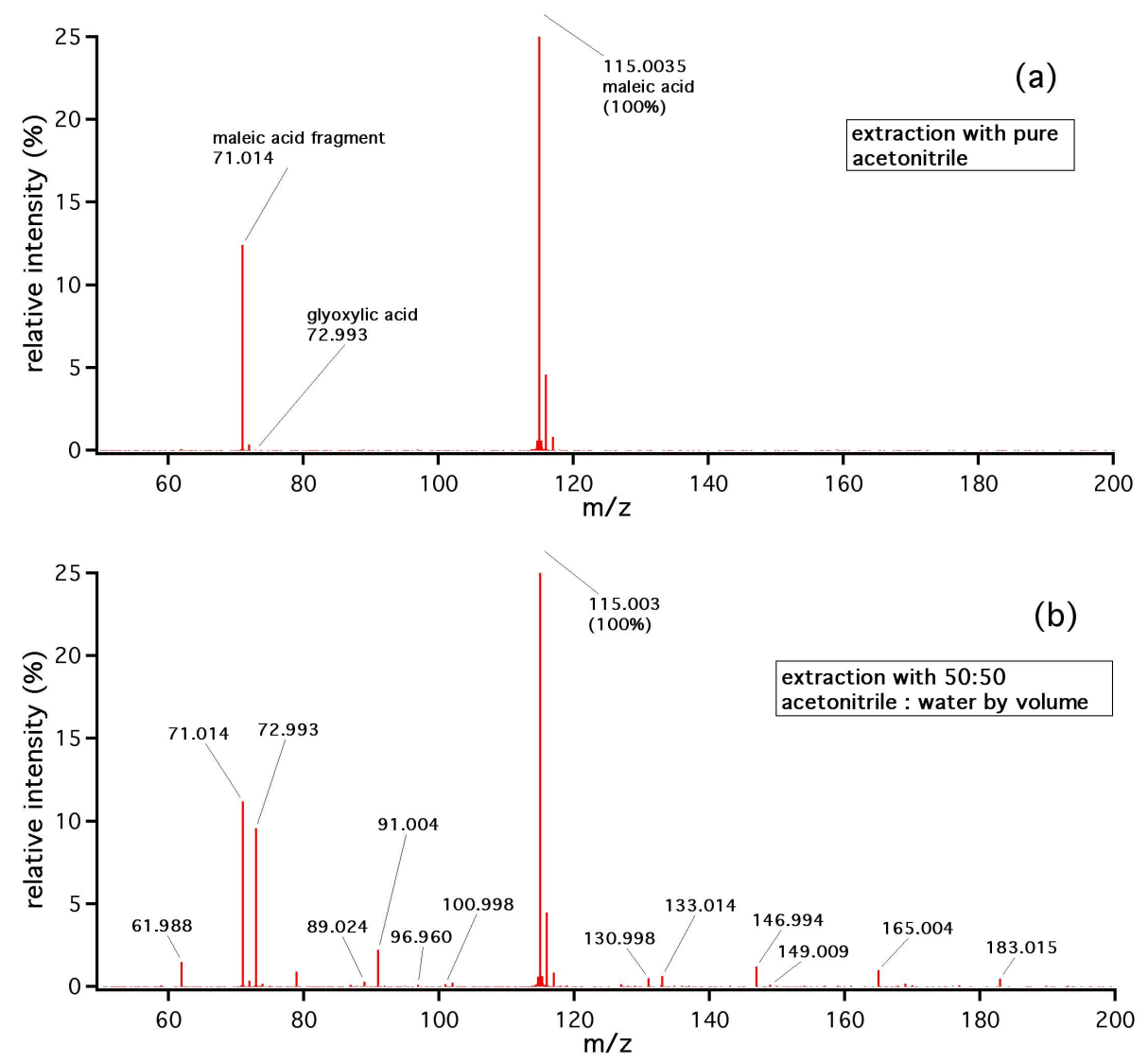

Fig. 5. Comparison of the mass spectra obtained for the same experimental run (dry ozonolysis of maleic acid particles on a Teflon filter) using different extraction techniques. For spectrum (a) the sample was extracted using pure acetonitrile and for spectrum (b) a 50:50 by volume mixture of water and acetonitrile was used as extraction solvent, demonstrating clearly the additional reactivity (and potential artefacts) induced by the aqueous extraction method.

These results are consistent with our previous work on maleic acid aerosol reactivity with ozone (Pope et al., 2010a) using an EDB. We found that the composition of maleic aerosol particles was strongly affected by the relative humidity to which a particle was exposed to during or after the ozonolysis reaction. We probed the composition by looking at the hygroscopicity and volatility of the aerosol. An increased water uptake was observed when the particle was oxidized under wet conditions compared to dry oxidation conditions, indicating that more compounds with high hygroscopicity are formed under high humidity conditions. It was also found that loss of aerosol mass via evaporation due to volatile oxidation products was only observed when the ozone processed aerosol was exposed to high RH, supporting more complex reaction schemes under wet conditions.

This work clearly demonstrates that the presence of water drastically changes the composition of the particles exposed to an oxidizing atmosphere and might affect its ability to act as cloud condensation nuclei.

\subsection{Solvent artefacts}

The previous discussion clearly shows that water critically affects the distribution of oxidation products of maleic acid exposed to ozone. Therefore it is important that the sample work up and extraction of the aerosol components from the filter does not introduce artefacts into the analysis, especially when water is used as an extraction solvent. To identify potential effects of the extraction procedure two different extraction solvents were compared. Both pure acetonitrile and $50 \%$ acetonitrile $/ 50 \%$ water by volume mixture were used as extraction media. Figure 5 shows the results of the two different extraction methods on the same filter, which was cut into two. Prior to extraction maleic acid was collected on the filter and exposed for $3 \mathrm{~h}$ to ozone under dry conditions. It can be clearly seen that the use of water as extraction solvent caused further reactions. All the peaks listed in Table 1 for the filter experiment are also seen in the dry ozonolysis sample extracted with acetonitrile/water (Fig. 5b). 


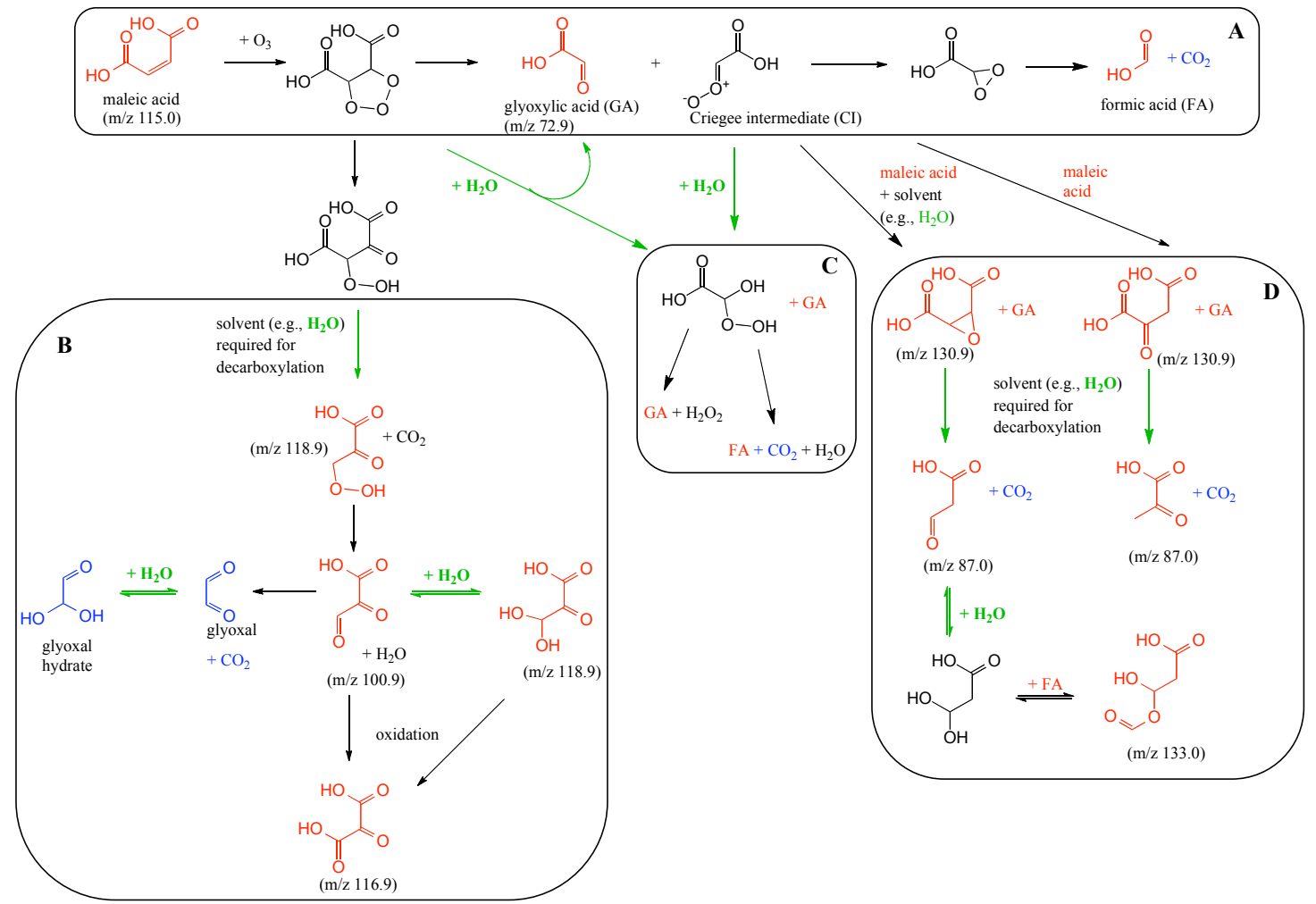

Fig. 6. Proposed mechanism for the reaction between ozone and maleic acid aerosol under dry and high RH conditions. Red: structures suggested for peaks observed in the mass spectra of this study, blue: observed by others, black: not observed, green: indicating reactions requiring water.

Different solubility of maleic acid oxidation products in acetonitrile compared to acetonitrile/water cannot explain the observed differences between Fig. 5a and b: all samples analyzed for Figs. 2-4 were extracted in pure acetonitrile and oxidation products were measured in intensities comparable to the filter extracted in acetonitrile/water (Fig. 5b). The oxidation products generated during aqueous extraction (Fig. 5b) are generally measured at lower intensities compared to high RH particle oxidation (Fig. 3b), which might be explained by the shorter interaction time between the oxidized maleic acid and the water or the more dilute concentrations of oxidation products in the water extracts.

This result indicates that water should be used with great care to extract organic aerosol from filters because of the extra reactivity which it might cause. For the analysis of ambient aerosol samples this might not be of serious concern because on average atmospheric particles have most likely experienced high-humidity conditions during their lifetime before sampling, except possibly in regions with very low $\mathrm{RH}$. But water-induced artefacts might well affect laboratory studies, which aim to identify detailed mechanisms of organic aerosol oxidation.

\subsection{Chemical mechanisms for the ozonolysis of wet and dry aerosol}

The difference in the mass spectra of particles oxidized under low or high RH conditions clearly indicates the importance of water upon aerosol reactivity. Figures 6-8 show a proposed reaction scheme of maleic acid ozonolysis accounting for most oxidation products found in this and in previous studies (Najera et al., 2009, 2010; Last et al., 2009; Leitzke and von Sonntag, 2009). Glyoxal and $\mathrm{CO}_{2}$ are oxidation products shown in Figs. 6-8, which are described in the literature but which could not be detected with the analytical technique used here.

It should be noted that the reaction scheme presented here relies only on suggestions in the literature and accurate mass determination in our study. To identify unambiguously structures for the masses determined here additional analyses such as chromatography or nuclear magnetic resonance spectroscopy would be needed.

Under dry conditions, the only oxidation product measurable here was glyoxylic acid (at $\mathrm{m} / z$ 72.993). Najera et al. (2009) further identified under dry conditions formic acid and possibly $\mathrm{CO}_{2}$ and oxalic acid. In our study oxalic acid was only found under high RH conditions. Step A in Fig. 6 
accounts for the formation of glyoxylic acid, formic acid, and $\mathrm{CO}_{2}$ under dry conditions. Glyoxylic acid is formed together with the Criegee intermediate, which could rearrange to a dioxirane intermediate and subsequently decompose to formic acid and $\mathrm{CO}_{2}$. To the best of our knowledge this reaction has not been previously suggested as an organic aerosol phase reaction. However, the reaction was previously suggested by Criegee (1975), and subsequently by Yamamoto et al. (1981) to explain the observed reaction products from the ozonolysis of $\alpha, \beta$-unsaturated carbonyl compounds. In the EDB experiments formic acid and $\mathrm{CO}_{2}$ would likely evaporate from the particle causing a loss of the particle mass. However, this was not observed under dry conditions. This apparent contradiction might be explained by the formation of oxidized intermediates on the particle surface compensating the mass loss of evaporating oxidation products.

Under high RH oxidation conditions Fig. 6 (step B-D) and Figs. 7-8 account for the formation of peaks at $\mathrm{m} / \mathrm{z} 87.0$, 88.9, 91.0, 100.9, 116.9, 118.9. 130.9, 133.0, 149.0, 146.9, 165.0, and 183.0, i.e. most of the peaks listed in Table 1.

The ozonide, formed by the $[2+3]$ cycloaddition of ozone with the double bond of maleic acid could rearrange to a hydroperoxide that decarboxylates in the presence of water to another hydroperoxide with a mass of $m / z$ 118.9, which could react further to $m / z, 100.9$, with a suggested structure given in Fig. 6, step B. The high reactivity of the ozonide with water is also described by Karagulian et al. (2008) where very similar water-dependent reaction routes are proposed. The compound at $\mathrm{m} / z, 100.9$ could be further oxidized to $\mathrm{m} / \mathrm{z} 116.9$ (addition of one oxygen), which decays to glyoxal and $\mathrm{CO}_{2}$ as suggested by Leitzke and von Sonntag (2009) or hydrate to give $\mathrm{m} / \mathrm{z}$ 118.9, which could also be oxidized to $\mathrm{m} / \mathrm{z} 116.9$. Potential oxidation agents could be $\mathrm{H}_{2} \mathrm{O}_{2}$, the Criegee intermediate or the dioxirane.

Step C illustrates another possible degradation route of the primary ozonide forming a hydroperoxide and glyoxylic acid. This mechanism is similar to that proposed previously by Leitzke and von Sonntag (2009) and Najero et al. (2010). The hydroperoxide is expected to further react to form formic acid and $\mathrm{CO}_{2}$ or $\mathrm{GA}$ and $\mathrm{H}_{2} \mathrm{O}_{2}$ as suggested by Karagulian et al. (2008). Alternatively the same hydroperoxide could form from the Criegee intermediate reacting with water.

It is postulated that the Criegee intermediate could react under humid conditions with maleic acid either to form an epoxide or as postulated by Last et al. (2009) and shown in step D, resulting in the formation of glyoxylic acid, and two compounds possibly explaining $\mathrm{m} / \mathrm{z}$ 130.9. Decarboxylation of $\mathrm{m} / \mathrm{z} 130.9$ leads to $\mathrm{m} / \mathrm{z}$ 87.0. The hydrate of 3oxopropanoic acid (one possible structure explaining $\mathrm{m} / \mathrm{z}$ 87.0) could react with formic acid to form an ester with mass $\mathrm{m} / \mathrm{z}$ 133.0.

Peaks at $\mathrm{m} / \mathrm{z} 87.0$ and 118.9 are explained in the proposed reaction scheme in Fig. 6 as products of decarboxylation reactions. However, these peaks could potentially also result from fragmentation within the mass spectrometer as it was

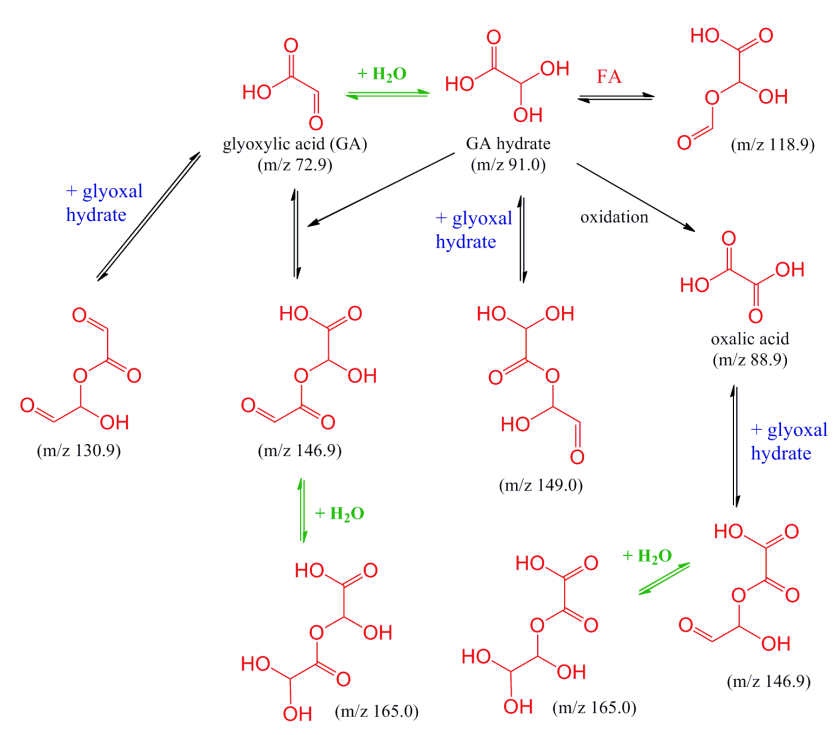

Fig. 7. Additional proposed reactions of maleic acid oxidation products under high RH conditions, involving glyoxylic acid or its hydrate. Colour code same as in Fig. 6.

observed for maleic acid (see Fig. 2a). We assume that such mass spectrometry artifacts are minimal because we observe possible reaction products of both decarboxylation products (i.e. $m / z, 100.9,116.9,133.0$ ), which could not be observed if these peaks would largely results from mass spectrometer artifacts.

Figure 7 describes possible reactions of glyoxylic acid and its hydrate in the presence of water. Oxidation of glyoxylic acid or its hydrate would produce oxalic acid $(\mathrm{m} / \mathrm{z} 88.9)$. Condensation reactions of these three products with formic acid and glyoxal hydrate could lead to a number of esters with masses at $m / z$ 118.9, 130.9, 146.9, 149.0. The hydrate of $\mathrm{m} / z 146.9$ at $\mathrm{m} / \mathrm{z} 165.0$ is also observed.

Four series of peaks were observed, which we tentatively assign as hydrate series: the first series involves glyoxylic acid and its hydrate at $m / z 72.9$ and 91.0 (Fig. 7) and the second series involves $\mathrm{m} / \mathrm{z}, 100.9$ and 118.9 (Fig. 6, step B). The third involves the mass peaks $\mathrm{m} / \mathrm{z}, 146.9$ and 165.0. The latter two series were only observed in filter experiments at RH $>90 \%$ or if the particles were extracted with water (Fig. 5b) indicating that these hydrates only form when a significant amount of water is present. Compounds at $\mathrm{m} / \mathrm{z} 146.9$ and 165.0 could be formed via reactions between glyoxal hydrate, glyoxylic acid, glyoxylic acid hydrate and oxalic acid as proposed by Lim et al. (2010) (Fig. 7). These reactions are not able to explain $\mathrm{m} / \mathrm{z}$ 183.0. A possible mechanism for the formation of $\mathrm{m} / z, 165.0$ and 183.0 is given in Fig. 8 suggesting a reaction between glyoxylic acid and the enol form of glyoxylic acid hydrate. Alternatively, a similar addition could be conceived between glyoxal hydrate and oxalic acid or glyoxylic acid hydrate and a ketene intermediate of glyoxylic acid, which could explain hydrates with masses at $\mathrm{m} / \mathrm{z}$ 


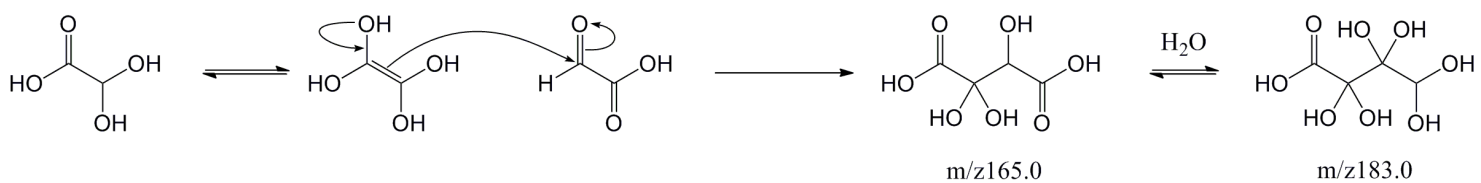

Fig. 8. Possible reaction schemes for the generation of the observed hydrate series with masses at $m / z, 165.0$ and 183.0 .

165.0 and 183.0. We have not been able to experimentally determine which of the reaction pathway(s) are responsible if any. It should be noted that both enols and ketenes are common intermediates observed in aqueous phase organic chemistry.

The overall loss rate of the aerosol mass under high $\mathrm{RH}$ conditions as determined in our previous EDB experiments appears to follow unimolecular first order kinetics which is consistent with the rate determining step being the cleavage of a weak hydroperoxide or peroxide bond with bond strength $\sim 100 \mathrm{~kJ} \mathrm{~mol}^{-1}$ or other compounds with similar bond strength e.g. secondary ozonides (Pope et al., 2010a; Hull et al., 1972). It should be highlighted that this speculative rate determining step was not based on chemical analysis, but could indicate that respective reactions in step $B$ and $\mathrm{C}$ in Fig. 6 might be rate limiting for the overall particle processing under high $\mathrm{RH}$ conditions.

It is notable that compounds usually observed in ozonolysis of unsaturated carboxylic acids, such as the reaction products of the addition of carboxylic acids and aldehydes to the Criegee intermediate and the Criegee intermediate self reaction are not detected here (except reactions of the Criegee intermediate with maleic acid). In addition, no oligomer series and other high-molecular weight compounds were observed, as detected in other laboratory organic aerosol models (e.g. oleic acid, Ziemann, 2005; Reynolds et al., 2006) or in ambient samples (e.g. Samburova et al., 2005). This could be explained by the higher electron deficiency of the Criegee intermediate from maleic acid due to the vicinal carbonyl group. This favours dioxirane formation and subsequent rapid decomposition to formic acid and $\mathrm{CO}_{2}$ under dry conditions. Under humid conditions the electron deficient Criegee intermediate of maleic acid is quenched by water more rapidly than the Criegee intermediate of oleic acid. The apparent differences in reactivity of the Criegee intermediate of maleic acid and oleic acid might also be explained by the slow kinetics of the maleic acid ozonolysis (evident from the long reaction time required), which is due to the conjugated structure of maleic acid. Consequently, reactions of the Criegee intermediate with other organic oxidation products are less likely compared to oleic acid oxidation where the kinetics are much faster and therefore reactants other than water are present in high concentrations compared to maleic acid particles. Alternatively, reaction products of the Criegee intermediate of maleic acid with carboxylic acids and aldehydes might be too unstable and decompose back to observed products.
These significant differences between maleic acid and oleic acid oxidation schemes clearly demonstrate that organic aerosol models have to be selected with care when findings are used to interpret field data. Higher oligomers are often detected in laboratory models systems (Kalberer et al., 2004; Reynolds et al., 2006) but less clearly observed in field samples (e.g. Samburova et al., 2005). Oleic acid, where high-mass oligomers are frequently observed and maleic acid where only dimers (but no higher oligomers) are detected could possibly be used to represent two opposing endpoints for model systems of particle phase reactivity for less oxidized and highly oxidized organic particles, respectively.

\subsection{Water: a reactant and determinant of particle phase}

The above discussion of Figs. 2 to 8 clearly shows that water is an important reactant in the maleic acid-ozone oxidation. While under dry conditions the formation of the Criegee intermediate is the dominant pathway, the presence of water seems to allow for a large number of additional reactions.

The maleic acid oxidation products with deliquescence points lower than maleic acid increase the water uptake of the particle below the deliquescence point of maleic acid (Fig. 4b). Such a water layer at the particle surface below deliquescence humidities allows for an increase in maleic acid oxidation as ozone can react with maleic acid dissolving into the surface water layer. This could result in a positive feedback to increase water uptake and oxidation reactions and a gradual solvation of the maleic acid particle bulk. In contrast, under dry conditions the reactivity is likely limited to the maleic acid present at the solid particle surface.

Results from Fig. 5 and from experiments with the EDB in our previous study (Pope, EST, 2010a) clearly show that maleic acid oxidation continues even hours after ozone exposure when the particles are exposed to water. This time lag in reactivity is difficult to interpret. Considering the reaction scheme in Fig. 6, reactive intermediates such as the ozonide might be stabilized on the dry particle surface and only react further if water is present on the particle surface.

\section{Conclusions}

The chemical composition of maleic acid aerosol particles after oxidation with ozone was investigated under varying relative humidities between $<5 \%$ and $90 \%$ using an ultra-high resoution mass spectrometer. Significant differences were 
observed between dry and high RH oxidation. Almost no reactivity and only glyoxylic acid was observed under dry ozonolysis conditions. In contrast, about 15 oxidation products were observed when the particles were exposed to ozone at relative humidties above about $50 \%$. This additional reactivity was observed well below the deliquescence point for maleic acid indicating that water likely serves as a reactant as well as allowing increased diffusion of ozone into the particle bulk and therefore increase reaction yields.

The chemical analyses complement very well hygroscopic growth results obtained with an EDB, which also show an increase in water uptake above about $50 \% \mathrm{RH}$ for oxidized particles. Thermodynamical modelling could convincingly explain this hygroscopic growth using the particle composition data obtained by the mass spectrometry analyses.

Maleic acid particles oxidized under dry conditions but extracted into an aqueous solvent demonstrate that the diverse reactivity observed under high $\mathrm{RH}$ ozonolysis conditions can be induced even when ozone was not present anymore, which may indicate a long-lived intermediate (possibly an ozonide) that reacts further once water is present in the system. This is consistent with observations of the EDB experiments. The additional reactivity induced by an aqueous extraction solvent also indicates that sample work up conditions have to be chosen with great care to avoid artefacts.

A reaction scheme is presented to account for most of the observed peaks in the mass spectra and related structures are postulated. Most oxidation products are highly oxygenated with peroxide, carboxylic acid or aldehyde functional groups. Compared to other organic aerosol systems (e.g. oleic acid, a model system frequently investigated in the past years) the diversity of oxidation products is larger and only dimers (mostly in the form of esters) were observed. No higher oligomers could be detected, which might be explained with the different structure and reactivity of the Criegee intermediate of maleic acid and oleic acid.

This study clearly shows that laboratory experiments investigating the chemical reactivity of organic aerosols need to include the combined effects of various atmospheric parameters (such as ozone and humidity) to account for the complex oxidation schemes in organic aerosol particles. The organic model system itself also needs careful consideration to represent the atmospheric complexity. Types of oxidation reactions may vary significantly depending on the model system, e.g. in oleic or maleic acid oxidation, and likely a variety of model systems need to be compared with ambient samples to identify the most relevant models.

Acknowledgements. This work was supported by the UK Natural Environment Research Council (NERC) and the Corporate Associate Scheme at the Department of Chemistry, University of Cambridge.

Edited by: M. C. Facchini

\section{References}

Choi, M. Y. and Chan, C. K.: Continuous measurements of the water activities of aqueous droplets of water-soluble organic compunds, J. Phys. Chem. A, 106, 4566-4572, 2002.

Clegg, S. L., Seinfeld, J. H., and Brimblecombe, P.: Thermodynamic modelling of aqueous aerosols containing electrolytes and dissolved organic compounds, J. Aerosol Sci. 32, 713-738, 2001.

Criegee, R.: Mechanism of Ozonolysis. Angewandte Chemie International Edition in English 14, 745-752, 1975.

Davis, E. J., Buehler, M. F., and Ward, T. L.: The double-ring electrodynamic balance for microparticle characterization, Rev. Sci. Instrum., 61, 1281-1288, 1989.

Fisseha, R., Dommen, J., Sax, M., Paulsen, D., Kalberer, M., Maurer, R., Höfler, F., and Baltensperger, U.: Identification of organic acids in secondary organic aerosol from chamber experiments, Anal. Chem., 76, 6535-6540, 2004.

Hull, L. A., Hisatsune, I. C., and Heicklen, J.: Vapor-Phase Thermal Decomposition of Some Simple Ozonides, J. Phys. Chem., 76, 2659-2665, 1972.

Kalberer, M., Paulsen, D., Sax, M., Steinbacher, M., Dommen, J., Fisseha, R., Prevot, A., Frankevich, V., Zenobi, R., and Baltensperger, U.: Identification of polymers as major components of atmospheric organic aerosols, Science, 303, 1659-1662, 2004.

Kamens, R. M., Zhang, H., Chen, E. H., Zhou, Y., Parikh, H. M., Wilson, R. L., Galloway, K. E., and Rosen, E. P.: Secondary organic aerosol formation from toluene in an atmospheric hydrocarbon mixture: Water and particle seed effects, Atmos. Environ., 45, 2324-2334, 2011.

Karagulian, F., Lee, A. S., Dilbeck, C. W., and Finlayson-Pitts, B. $\mathrm{J}$.: A new mechanism for ozonolysis of unsaturated organics on solids: phosphocholines on $\mathrm{NaCl}$ as a model for sea salt particles, Phys. Chem. Chem. Phys., 10, 528-541, 2008..

Kawamura, K., Kasukabe, H., and Barrie, L. A.: Secondary formation of water soluble organic acids and $\alpha$-dicarbonyls and their contributions to total carbon and water-soluble organic carbon: Photochemical aging of organic aerosols in the Arctic spring, J. Geophys. Res., 115, D21306, doi:10.1029/2010JD014299, 2010.

Kundu, S. Kawamura, K., and Lee, M.: Seasonal variations of diacids, ketoacids, and $\alpha$-dicarbonyls in aerosols at Gosan, Jeju Island, South Korea: implications for sources, formation, and degradation during long-range transport, J. Geophys. Res., 115, D19307, doi:10.1029/2010JD013973, 2010.

Last, D. J., Najera, J. J., Wamsley, R., Hilton, G., McGillen, M., Percival, C. J., and Horn, A. B.: Ozonolysis of organic compounds and mixtures in solution. Part I: Oleic, maleic, nonanoic and benzoic acids, Phys. Chem. Chem. Phys., 11, 1427-1440, 2009.

Lee, A. K. Y. and Chan, C. K.: Heterogeneous reactions of linoleic acid and linolenic acid particles with ozone: reaction pathways and changes in particle mass, hygroscopicity, and morphology, J. Phys. Chem. A, 111, 6285-6295, 2007.

Leitzke, A. and von Sonntag, C.: Ozonolysis of unsaturated acids in aqueous solution: acrylic, methacrylic, maleic, fumaric and muconic acids, OS\&E 31, 301-308, 2009.

Li, Y.-C. and Yu, Y. Z.: Simultaneous Determination of Mono- and Dicarboxylic Acids, Oxo-carboxylic Acids, Midchain Ketocarboxylic Acids, and Aldehydes in Atmospheric Aerosol Samples, Environ. Sci. Technol., 39, 7616-7624, 2005.

Lim, Y. B., Tan, Y., Perri, M. J., Seitzinger, S. P., and Turpin, 
B. J.: Aqueous chemistry and its role in secondary organic aerosol (SOA) formation, Atmos. Chem. Phys., 10, 1052110539, doi:10.5194/acp-10-10521-2010, 2010.

Nájera, J. J., Percival, C. J., and Horn, A. B.: Infrared spectroscopic studies of the heterogeneous reaction of ozone with dry maleic and fumaric acid aerosol particles, Phys. Chem. Chem. Phys., 11, 9093-9103, 2009.

Nájera, J. J., Percival, C. J., and Horn, A. B.: Kinetic studies of the heterogeneous oxidation of maleic and fumaric acid aerosols by ozone under conditions of high relative humidity, Phys. Chem. Chem. Phys., 12, 11417-11427, 2010.

Nguyen, T. B., Roach, P. J., Laskin, J., Laskin, A., and Nizkorodov, S. A.: Effect of humidity on the composition of isoprene photooxidation secondary organic aerosol, Atmos. Chem. Phys., 11, 6931-6944, doi:10.5194/acp-11-6931-2011, 2011.

Peng, C., Chan, M. N., and Chan, C. K.: The hygroscopic properties of dicarboxylic and multifunctional acids: Measurements and UNIFAC predictions, Environ. Sci. Technol., 35, 4495-4501, doi:10.1021/es0107531, 2001.

Pfrang, C., Shiraiwa, M., and Pöschl, U.: Chemical ageing and transformation of diffusivity in semi-solid multi-component organic aerosol particles, Atmos. Chem. Phys., 11, 7343-7354, doi:10.5194/acp-11-7343-2011, 2011.

Pope, F. D., Gallimore, P. J., Fuller, S. J., Cox, R. A., and Kalberer, M.: Ozonolysis of Maleic Acid Aerosols: Effect upon Aerosol Hygroscopicity, Phase and Mass, Environ. Sci. Technol., 44, 6656-6660, 2010a.

Pope, F. D., Dennis-Smither, B. J., Griffiths, P. T., Clegg, S. L., and Cox, R. A.: Studies of single aerosol particles containing of malonic acid, glutaric acid, and their mixtures with sodium chloride. I. Hygroscopic growth, J. Phys. Chem. A, 114, 53355341, 2010b.

Pope, F. D., Tong, H. J., Dennis-Smither, B. J., Griffiths, P. T., Clegg, S. L., Reid, J. P., and Cox R. A.: Studies of Single Aerosol Particles Containing Malonic Acid, Glutaric Acid, and Their Mixtures with Sodium Chloride. II. Liquid-State Vapor Pressures of the Acids, J. Phys. Chem. A, 114,10156-10165, 2010c.

Reynolds, J. C., Last, D. J., McGillen, M., Nijs, J. A., Horn, A. B., Percival, C., Carpenter, L. J., and Lewis, A. C.: Structural Analysis of Oligomeric Molecules Formed from the Reaction Products of Oleic Acid Ozonolysis, Environ. Sci. Technol., 40, 6674-6681, 2006.
Samburova, V., Szidat, S., Hueglin, C., Fisseha, R., Baltensperger, U., Zenobi, R., and Kalberer, M.: Seasonal variation of high molecular weight compounds in the water-soluble organic fraction of urban aerosols, J. Geophys. Res., 110, D23210, doi:10.1029/2005JD005910, 2005.

Shiraiwa, M., Ammann, M., Koop, T., and Pöschl, U.: Gas uptake and chemical aging of semisolid organic aerosol particles, P. Natl. Acad. Sci., 108, 11003-11008, doi:10.1073/pnas.1103045108, 2011.

Vesna, O., Sax, M., Kalberer, M., Gaschen, A., and Ammann, M.: Product study of oleic acid ozonolysis as function of humidity, Atmos. Environ., 43, 3662-3669, 2009.

Vesna, O., Sjogren, S., Weingartner, E., Samburova, V., Kalberer, M., Gäggeler, H. W., and Ammann, M.: Changes of fatty acid aerosol hygroscopicity induced by ozonolysis under humid conditions, Atmos. Chem. Phys., 8, 4683-4690, doi:10.5194/acp-84683-2008, 2008.

Wexler, A. S. and Clegg, S. L.: Atmospheric aerosol models for systems including the ions $\mathrm{H}^{+}, \mathrm{NH}_{4}^{+}, \mathrm{Na}^{+}, \mathrm{SO}_{4}^{2-}$, $\mathrm{NO}_{3}^{-}, \mathrm{Cl}^{-}, \mathrm{Br}^{-}$, and $\mathrm{H}_{2} \mathrm{O}$, J. Geophys. Res., 107, 4207, doi:10.1029/2001JD000451, 2002.

Wittig, R., Lohman, J., and Gmehling, J.: Vapor-Liquid Equilibria by UNIFAC Group Contribution. 6. Revision and Extension, Ind. Eng. Chem. Res., 42, 183, 2003.

Yamamoto, Y., Niki, E., and Kamiya, Y.: Ozonation of organic compounds. 4. Ozonolysis of $\alpha, \beta$-unsaturated carbonyl compounds in protic solvents, Journal of Organic Chemistry, 46, 250-254, 1981.

Zahardis, J. and Petrucci, G. A.: The oleic acid-ozone heterogeneous reaction system: products, kinetics, secondary chemistry, and atmospheric implications of a model system - a review, Atmos. Chem. Phys., 7, 1237-1274, doi:10.5194/acp-7-1237-2007, 2007.

Ziemann, P. J.: Aerosol products, mechanisms, and kinetics of heterogeneous reactions of ozone with oleic acid in pure and mixed particles, Faraday Discuss., 130, 469-490, 2005. 